\title{
Risk sharing and capacity investment in the urban water sector in Europe
}

\author{
P. Luís-Manso \& M. Finger \\ École Polytechnique Fédérale de Lausanne, Switzerland
}

\begin{abstract}
Environmental standards in the urban water sector have become increasingly stringent in Europe, which consequently increases the cost of water and sanitation services. In conjunction with the crisis of public finance in many regions, these standards are pressing the traditional way of financing through the public budget. Moreover, the infrastructure network is ageing in many countries and thus there is a considerable demand for renewal investments. Efficiency, underinvestment and environmental problems have therefore triggered important reforms in the urban water sector in the past decade. These reforms are creating new sources of uncertainty and vulnerability related to the management and regulation of water utilities. They are a result of the emergence of new actors playing an active role in the sector, as well as the "unbundling" of managerial and regulatory functions. As a matter of fact, the multiplication of the actors in the urban water sector, and new institutional arrangements diffusing responsibilities traditionally concentrated on publicly owned integrated utilities, raises new issues one of the most important being the sustainability of capacity investment. Risk management, including the change of risk sharing patterns, is an essential decision in water management and has considerable influence on investment. This paper thus focuses on the main elements at risk by the reform of the sector, namely capacity investment, and how these risks are shared between different actors for the most representative institutional arrangements in the European urban water sector.

Keywords: urban water sector, reform, risk sharing, capacity investment, institutional arrangements.
\end{abstract}




\section{Introduction}

Traditionally, urban water services were characterised by local monopolies, where the incumbent was local authority-owned. This can be explained by several reasons related to water sector specificities, ranging from safety and health to economic and technological reasons. However, in spite of all that, in the past decade the urban water sector has undergone important reforms, triggered by efficiency, underinvestment and environmental problems.

Today, there are three dominant institutional arrangements in Europe:

- Direct public management $\left(D_{i r} P_{u b} M\right)$;

- Delegated management by leasing $\left(D M_{l e a}\right)$ or concession $\left(D M_{c o n}\right)$;

- Direct private management with independent regulation $\left(D_{i r} P_{r i} M\right)$.

The traditional and still the most common institutional arrangement is direct public management. The public operator is both responsible for the regulation and the provision of the service, and manager of the system. However, delegated management grounded on agreements between autonomous actors, such as delegation contracts, are becoming very important (hybrid) forms of coordination in the water sector. These contracts can take various forms, namely concession, leasing, and intermediary management. The main feature of concession is that the infrastructure is financed by the concessionaire (i.e., the firm who operates the concession). The concessionaire also operates the service. Lease contracts provide a means for firms to purchase the income streams generated by publicly owned assets in exchange for a fixed lease payment and the obligation to operate and maintain the assets (Euromarket [5]). Finally, there is the case of England and Wales where water utilities were privatised and a strong independent regulator was created.

The reforms have created a new environment for urban water management, as well as new sources of uncertainty and vulnerability, which consequently affect risk. Risk is herein defined as a function of the hazard, the impact on the elements at risk, and vulnerability. The term "risk" in the water sector is used to express the probability of an area or a group of economic actors "to be affected" by a phenomenon, event or process, taking into account the elements at risk (e.g., integrity of the network system, human health) and the vulnerability of the actors regarding the event.

The paper starts out by describing the main features of the reforming process. It follows the identification of the main elements at risk by the reform of the sector, differentiating between those that are common to all network industries and those that are exacerbated by water sector specificities. A special focus is given in the paper to capacity investment. Finally, the paper focuses on the way capacity investment related risks are shared between different actors for the most representative institutional arrangements in the European water sector.

\section{Features of the reforming process in the sector}

In the early stages of the process of restructuring the network industries, there was a shift from public to private ownership. There were several reasons on the 
grounds of the decision to involve the private sector. One of the most important was the increase in operational efficiencies. Other authors presented other reasons, such as reducing the public sector borrowing requirement, and reducing government involvement in enterprise decision making (Vickers and Yarrow [1]).

Gradually, contradictory findings on the relation between ownership and efficiency questioned the purpose of privatisation. Some authors argued that the restructuring of the network industries should instead result from the introduction of competition, i.e., from liberalisation (e.g., Armstrong [2], Newbery [3], Vickers and Yarrow [4]).

In spite of the specificities of water supply and sanitation, the sector has undergone important reforms in many countries, triggered by economic, financial, managerial and ideological factors. Table 1 summarises the main trends in the sector, before and after the reform processes. It is important to note that the reform processes are not all characterised by the same trends.

However, there are trends characterising the majority of the reforms, such as the efforts to introduce competition, private sector participation, regionalisation, and professionalisation of water services. These are developed in more detail below.

Table 1: $\quad$ Main trends before and after reform.

\begin{tabular}{l|l|l}
\hline & \multicolumn{1}{|c}{ Pre-reform } & \multicolumn{1}{c}{ Post-reform } \\
\hline Owner of the infrastructure & Public/municipalities & Mainly public \\
\hline Scale of infrastructure & Local & $\begin{array}{l}\text { Local } \\
\text { Link local networks into regional }\end{array}$ \\
\hline Operator's characteristics & $\begin{array}{l}\text { Local operator (mainly } \\
\text { municipalities) }\end{array}$ & $\begin{array}{l}\text { Local/regional/trans-national } \\
\text { Increased private participation }\end{array}$ \\
\hline Operator's objectives & $\begin{array}{l}\text { Public services } \\
\text { Public policies }\end{array}$ & Public services with profit \\
\hline Financing & Cross-subsidies & Cost-recovery \\
\hline Operation versus regulation & Integrated & $\begin{array}{l}\text { Integrated } \\
\text { Separated (with reg. agency) }\end{array}$ \\
\hline Main objectives of regulation & $\begin{array}{l}\text { Public health } \\
\text { Public service }\end{array}$ & $\begin{array}{l}\text { Public health } \\
\text { Environmental protection } \\
\text { Public service obligations } \\
\text { Market structure }\end{array}$ \\
& & $\begin{array}{l}\text { Competition for the market } \\
\text { Comparative competition }\end{array}$ \\
\hline Type of liberalisation & No liberalisation \\
& Local monopoly &
\end{tabular}

\subsection{Introduction of competition / liberalisation}

There are three different routes to establishing the conditions of market rules and competition (i.e., to liberalise): competition in the market (operators compete for end users); competition for the market (operators compete for obtaining exclusive rights to operate in specific segments); and comparative competition.

In the urban water sector, competition in the market is difficult to implement due to strong economies of scale or to the obligation to provide services of general interest. One alternative in these cases is to institute competition ex-ante, 
i.e. competition for the market. It occurs when potential (public or private) operators bid competitively for a delegation contract. When direct competition (in and/or for the market) cannot be created, a method currently used is to compare performance of operators in different geographical areas but on similar services. This is called yardstick or comparative competition. The comparisons can be made for segments of the utilities' operations and can cover a range of variables such as capital maintenance costs, operating costs, prices, or quality of service.

\subsection{Private sector participation (PSP)}

The private sector may be an important source of capital, which is relatively scarce for many countries. It also brings management expertise, new technologies and knowledge. One of the key features brought about by the PSP is the shift in business models from the public service to the public service with a profit goal regime. However, even under the traditional public procurement model, public authorities rely on the private sector for design, construction, and management services.

Especially for higher degrees of PSP, such as divestiture, there are lower degrees of public involvement and public accountability. Private entities are accountable to shareholders rather than to the public. This also coincides with the passage from tax payer citizens to bill payer consumers.

\subsection{Regionalisation}

Although the water network utility has been justly described as a natural local monopoly, some trends towards regionalisation are extending the geographic impact of the so-called local monopoly. Regionalisation of urban water services' management refers to an increase in the scale of water services, often due to a grouping of municipalities. Its rationale lies in the fact that the small size of suppliers actually limits the benefits that can be derived from economies of scale.

\subsection{Professionalisation of water services}

The drivers of change in the sector do not necessarily lead to increased competition and private sector participation. In many countries, the alternative approach to liberalisation relies on giving enough autonomy to public utilities, in order that the business principles and practices can be adhered to. The increasing autonomy of water management in relation to politics, as well as the professionalisation of (public) water services is an important trend. Local authorities remain in the majority of the cases the owners of the assets. The most common cases are the transformation of organic units within the local public authority structures into autonomous organisations possessing sole decisionmaking competency at all levels of managerial action.

The purpose of the next chapter is to identify the main elements at risk by the reform of network industries, with a special emphasis on the urban water sector. 


\section{Elements at risk by the reform of the sector}

The risks resulting from the reform of network industries are defined as the variability in/added to the total social benefit from the provision of these services in terms of security of supply, integrity of the system, equity of access, and affordability of prices, all resulting from the liberalisation of the sector. It is important to say that liberalisation is not considered a hazard per se. The point here is that the process of liberalisation potentially creates hazards, i.e., creates the probability of occurrence of damaging events, phenomena or processes.

Table 2: $\quad$ Categories of risk in network industries.

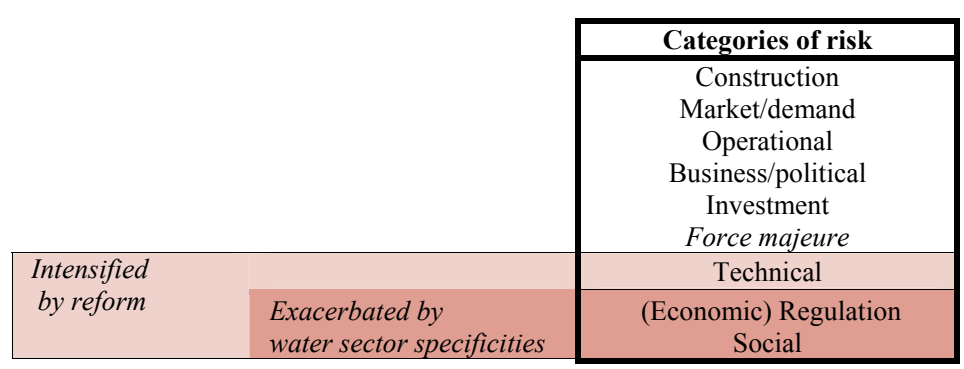

There are risks common to all network industries faced by the responsible entity for the management of the system. Firstly, there are construction risks in case contractors do not finish the project on time, within budget and according to the contract specifications. Secondly, there are market risks related to demand, namely to the ability and willingness to pay for water services. Thirdly, there are operational risks pertaining to the facilities' failure to meet performance parameters, including those related to quality. Fourthly, there are business risks specifically related to financial and political hazards. Fifthly, there are investment risks faced by lenders and investors, which pertain to currency exchange fluctuations and the disparity between domestic-currency revenue and international borrowing; and repayment of the credit. One must also mention force majeure risks faced by all the actors (i.e., contracting parties), which are related to events beyond their control and that enable either party to suspend obligations under the contract. Finally, technical risks pertain to the functioning of technical systems, namely to interoperability, interconnection, and capacity management. Technical risks are intensified by the reform processes in these industries, more specifically by the unbundling and fragmentation of the technical systems, which are normally required when introducing competition.

Institutional and economic specificities of the water sector create additional obstacles to managing and regulating the systems. Strong environmental and public health externalities related to the provision of water services reinforce the multiplicity of public policy objectives. In the context of a reform process (e.g., when the service is provided by private operators), these externalities exacerbate the need to regulate, thus augmenting the regulatory risks faced by the management entity. Social risks are related to the provision and financing of public service obligations, which had been traditionally guaranteed by public 
ownership and provision of the services. In a context of liberalisation, social risks pertain to the possibility that the provider of the service raises tariffs to socially unacceptable levels since users are captive. It may also carry out a selective expansion of activities to the most profitable segments (i.e., creamskimming), endangering the financing of non-profitable segments. At last, with the end of cross-subsidisation, the costs and benefits of liberalisation may be unevenly distributed. It is interesting to note that the risks exacerbated by the specificities of the urban water sector are also intensified by the reform of the sector, and more precisely by liberalisation.

Table 3: $\quad$ Risk allocation per institutional arrangement.

\begin{tabular}{l|cccc}
\hline Category of risk & \multicolumn{4}{|c}{ Risk allocation } \\
& $D_{i r} P_{u b} M$ & $D M_{\text {lea }}$ & $D M_{c o n}$ & $D_{i r} P_{r i} M$ \\
\hline Construction & & $\mathrm{PA}$ & $\mathrm{O}$ & $\mathrm{O}_{p r i}$ \\
Market & & $\mathrm{PA}$ & $\mathrm{O}$ & $\mathrm{O}_{p r i}$ \\
Operational & & $\mathrm{O}$ & $\mathrm{O}$ & $\mathrm{O}_{p r i}$ \\
Business/political & $\mathrm{RE}$ & $\mathrm{O}$ & $\mathrm{O}$ & $\mathrm{O}_{p r i}$ \\
Investment & $\approx$ & $\mathrm{PA}$ & $\mathrm{O}$ & $\mathrm{O}_{p r i}$ \\
Technical & $\mathrm{O}_{p u b}$ & $\mathrm{PA}$ & $\mathrm{PA} / \mathrm{O}$ & $\mathrm{O}_{p r i}$ \\
(Ec.) Regulation & & $\mathrm{O}$ & $\mathrm{O}$ & $\mathrm{O}_{p r i}$ \\
Social & & $\mathrm{PA}$ & $\mathrm{PA}$ & $\mathrm{PA}$ \\
Force majeure & & $\mathrm{all}$ & $\mathrm{All}$ & all \\
\hline
\end{tabular}

Table 3 presents the allocation of risks between the responsible and management entities, namely the public authority (PA) and the operator $(\mathrm{O})$, which can be public $\left(\mathrm{O}_{p u b}\right)$ or private $\left(\mathrm{O}_{p r i}\right)$, for the different institutional arrangements. From the risks affected by the reform of the sector (in colour), it is the allocation of technical risks that differ the most across arrangements.

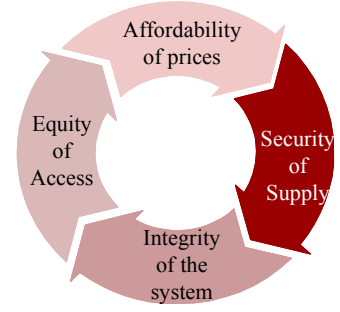

Figure 1: $\quad$ Elements at risk in a liberalised context.

The most important "elements at risk" in network industries resulting both from the nature of competition, the means of its implementation (PSP and unbundling of management and regulatory activities are considered the most significant ones), and its accompanying mechanisms (e.g., cream-skimming); pertain to integrity of the system, security of supply, equity of access, and affordability of prices (Figure 1). The vulnerability of these elements at risk is particularly important in the water sector and results from the combination of several factors, namely (1) existence of natural monopolies in certain segments of the sector; (2) low price elasticity of demand (for primary uses of water); and (3) important externalities related to the provision of water services. 


\section{Capacity investment: element at risk during reform}

The focus is given to capacity investments, which is a fundamental component of security of supply and integrity of the system. The total costs of running a water system encompass operating costs and capital costs. Capacity investment is meant to cover capital costs. The execution and efficacy of capacity investments is thus essential for the overall quality of the system. The output quality of capacity investments can be measured by indicators such as the performance of the system, percentage of leakages and asset conditions, as well as safety conditions.

After identifying the elements at risk by the reform of the sector, it is essential to analyse what influences their vulnerability. In this way, the vulnerability of capacity investments in the urban water sector mainly depends upon the factors identified below.

Long asset durability is based on large sunk investments with long payback periods. On the one hand, the corresponding long amortisation periods enable the water company to maintain low tariff levels and to operate for years without recovering its fixed costs (Noll et al. [6]). In a context where the management is delegated to a third party (whose private goals may differ from public ones) for a limited time, this may trigger opportunistic behaviour of the operator. It may under-invest in capacity for a long time before the consequences are visible. This is aggravated if the delegated contract duration is shorter than the life of the asset. The limit is the point where the operator begins to under-invest in maintenance and expansion of the network (Shirley et al. [7]). On the other hand, long asset durability increases specification costs, consequently augmenting transaction costs related to contract design and enforcement.

High fragmentation of the sector's structure is explained by the local character of water natural monopolies. The high fragmentation of the structure of the sector means that there are many small size management entities (in contrast to other network industries where the incumbent is a national one). Coupled with large, sunk and durable investments, many small size operators actually increase credit related transaction costs. Regionalisation, one of the main trends in the reforming process, is actually increasing the scale of water services, which decreases the vulnerability of capacity investment.

Uncertainty related to the real conditions of the network is due to underground assets. The high degree of uncertainty renders more difficult the valuation of assets and, consequently, the correct definition of investment plans. This is particularly important for contracts because uncertainty increases the writing, renegotiation, and (re)tendering costs.

Risk of opportunistic behaviour by public authorities. This is clearly one of the vulnerability factors originating from the reform process of the sector, especially in the event of private sector participation. The main issue pertains to the hold-up problem. Authorities may be tempted to change the rules (in response to popular pressures) knowing that private investors cannot withdraw easily from capacity investments characterised by capital intensity, durability 
and sunkness of costs (Gómez-Ibáñez [8]). Such an attitude makes future negotiations to renew the investment highly unlikely.

Constraints of public finance and underdevelopment of capital markets: the main source of vulnerability is related to the scarcity of local financing and it is in fact one of the main factors of change triggering the reform of the sector.

In sum, two of the factors are actually intensifying the vulnerability of capacity investment in the event of liberalisation (more precisely, features characterising the reform of the sector). These are asset durability and uncertainty over the real conditions of the network. Opportunistic behaviour by public authorities is only considered in the context of transfer of responsibilities (not significant otherwise). Finally, two other factors may be mitigated by some features of the reform process, namely fragmentation of the sector's structure if there is a trend towards regionalisation and constraint of local financing if the reform actually leads to a larger mobilisation of (private) capital to the sector.

\section{Risk sharing across different institutional arrangements}

An essential objective in risk management is to properly identify and clearly (re)allocate the risks to the parties that are in the best position to mitigate them. The current chapter aims at comparing the factors affecting the vulnerability of capacity investment, and at identifying how these risks shared between actors in the main institutional arrangements in Europe (Table 4).

Table 4: Vulnerability of capacity investments.

\begin{tabular}{l|cccc}
\hline & \multicolumn{4}{|c}{ Vulnerability of capacity investment } \\
Factors & $D_{i r} P_{u b} M$ & $D M_{l e a}$ & $D M_{c o n}$ & $D_{i r} P_{r i} M$ \\
\hline Asset durability & - & - & ++ & - \\
Fragmentation & + & + & + & - \\
Asset valuation & - & - & ++ & + \\
Opportunistic behaviour & - & - & + & + \\
Financial constraints & ++ & + & - & - \\
\hline Risk taker & $\mathrm{O}_{p u b}$ & PA & $\mathrm{O}$ & $\mathrm{O}_{p r i}$ \\
\hline
\end{tabular}

In this comparison, it is important to consider the costs created by the reforming process and that influence incentives to invest (Table 5). These costs are related to the factors of vulnerability and, therefore, their level influences the degree of incentives. The list however is not comprehensive and there are other aspects affecting the vulnerability of capacity investment.

Compared to other institutional arrangements, the main factors affecting the vulnerability of capacity investment under Direct Public Management are fragmentation of the sector's structure and constraints on public finance. In many cases in Europe, the fragmentation factor is being attenuated by a trend towards the concentration of local systems under the same management structure. As for the financing factor, it has been attenuated by Cohesion Funds in selected countries. The responsible entity for capacity investment is the public operator.

The analysis regarding Delegated Management by Leasing is similar to the previous one in the sense that the responsibility to invest in capacity remains 
with the (local) public authority. One difference may lay in the lower importance of the financial constraint factor (i.e., weaker vulnerability) due to efficiency gains at the managerial level obtained by leasing.

Table 5: $\quad$ Costs related to the vulnerability factors.

\begin{tabular}{l|l}
\hline Factors & Costs \\
\hline Asset durability & Specification \\
\hline Fragmentation & Transaction \\
\hline Asset valuation & Renegotiation \\
\hline Opportunistic behaviour & Re-tendering \\
\hline Financial constraints & Capital \\
\hline
\end{tabular}

As for Delegated Management by Concessions, there is delegation of the responsibility to invest in capacity to the operator (can be private or public) for a pre-defined period. This raises the vulnerability of capacity investment in different ways. First, due to asset durability, specification costs are higher than in institutional arrangements where there is no transfer of such responsibility (i.e., for direct public management and leasing). The same rationale applies to transaction costs related to renegotiation and (re)tendering, which are by definition negligible when there is no contract to delegate this responsibility, i.e., direct management and leasing. The operator is moreover exposed to the hold-up risk, which increases the vulnerability of capacity investment. As for financial constraints, the analysis is not conclusive. We nonetheless consider that the private sector is able to mobilise more capital and in a faster and cheaper way than local public entities. This is due to the crisis of the public finances, as well as to restructuring measures that in many cases follow the delegation by concessions (e.g., full cost recovery).

The assessment of the vulnerability in the Direct Private Management case highly depends on the efficacy and independence of the regulator. The responsible entity for capacity investment is the private operator. It is considered to be an intermediate case because even though there is no need to write a contract, regulatory functions call for some type of specification and valuation of assets. This model represents the case in England and Wales, where the sector is organised at a regional level. The fragmentation factor is thus negligible.

\section{Conclusions}

The acceptable level of risk related to the reform of the sector, and to liberalisation in particular, is the one which individuals, businesses, and governments are willing to accept in return for the perceived benefits. It depends on the information related to the hazard, as well as on economic, social, and political factors specific to the group that is threatened by that hazard.

Within the main elements at risk by reform, capacity investment is one of the most important because it is essential for the sustainability of the system and the quality of the service. The analysis of the factors affecting its vulnerability as 
well as their comparison across different institutional arrangement provided essential information in terms of risk management.

The vulnerability factors affect capacity investment in different ways and degrees, depending on the institutional arrangement. All else being equal, delegation management by concessions is the most vulnerable arrangement in terms of capacity investment. This is because the delegation of responsibilities for a limited period intensifies the vulnerability of investment due to the characteristics of the assets, as well as the exposition of the actors to opportunistic behaviour from partners. Moreover, the main risk taker is the concessionaire, who is not the owner of the assets and whose responsibilities are limited in time. This leads us to the next conclusion.

The degree of incentives is correlated to the way risks and transaction costs are shared between the actors. After the identifications of what is at risk and how this is shared between actors, the definition of coherent and adapted risk mitigation strategies to specific institutional arrangements is the following step for an efficient risk management policy. Capacity investment related risk is better taken by the operator, who has access to better information about the system. Moreover, it is in its best interest to have an efficient system to run the service. However, the incentive to invest in capacity is weakened by limited delegation periods and if the asset is not owned by the operator. Finally, the private incentive to invest in capacity does not necessarily correspond to public goals. In these contexts, the authors are working on new institutional dimensions that tackle the problems highlighted by each arrangement, in order to weaken the identified vulnerability factors and, consequently, increase incentives to invest in capacity that corresponds to public policy objectives set for the sector.

\section{References}

[1] Vickers, J. \& Yarrow, G., Privatization: an Economic Analysis, The MIT Press: Cambridge, MA, 1988.

[2] Armstrong, M., Privatisation, Regulation and Competition. Competition and Development Conference, South Africa, 2003.

[3] Newbery, D., Regulating Unbundled Network Utilities. The Economic and Social Review, 33, pp. 23-41, 2002.

[4] Vickers, J. \& Yarrow, G., Economic Perspectives on Privatization. Journal of Economic Perspectives 5, pp. 111-132, 1991.

[5] Analysis of the European Union Explicit and Implicit Policies and Approaches in the Larger Water Sector; Final Report for the Euromarket project, Online. www.epfl.ch/mir/euromarket, 2003.

[6] Noll, R., Shirley, M. \& Cowan, S. Reforming Urban Water Systems in Developing Countries. Economic Policy Reform: The Second Stage, ed. A. O. Krueger, University of Chicago Press: Chicago, 2000.

[7] Shirley, M., Xu, L. \& Zuluaga, C.A., Reforming Urban Water Supply: The Case of Chile. Policy Research Working Papers, WB: Washington, 2000.

[8] Gómez-Ibáñez, J., Regulating Infrastructure: monopoly, contracts, and discretion, Harvard University Press: Cambridge, MA, 2003. 